JELTL (Journal of English Language Teaching and Linguistics) e-ISSN: 2502-6062, p-ISSN: 2503-1848

2019, Vol. 4(2)

www.jeltl.org

\title{
Two Uses of Gender in Conversation: A Membership Categorization Analysis
}

\author{
Bouhout Najib \\ University Ibn Zohr, Agadir, Morocco \\ najib.bouhout@usmba.ac.ma
}

\begin{abstract}
Discourse analysts have for a long time focused on the study of gender differences in language. Recent approaches, however, eschew that concern in favor of studying the performative aspects of gender. In line with this, Membership Categorization analysis offers the additional advantage of studying societal members' gender categorization in conversation, the way it shapes the course of conversation, and its import, and consequences, for the conduct of participants in interaction. Membership Categorization Analysis is used here to spot some practical uses of gender by interactants in mundane talk among friends. More specifically, the article analyses two conversational instances where interactants deploy the categories 'men' and 'manly practices' to realize particular actions in conversation (suggestion and blame attribution). One finding is that gender categorization does pragmatic actions in interaction. In addition, the article argues that the relevance of gender, as one textual given among many, must be analytically demonstrated empirically in the conduct of interactants rather than invoked for the theoretical concerns of the discourse analyst.
\end{abstract}

Keywords: gender, discourse, Membership Categorization Analysis, action, conversation

\section{INTRODUCTION}

The field of gender and discourse has come a long way since the first breakthroughs of the seventies. Notwithstanding their achievement, the outcome of early studies, according to Smith (1985), was "a myopic concentration of research on sex differences" (p. 16). An alternative paradigm that has gained grounds, given the shortcomings of a focus on gender differences (Burr, 1995; Speer, 2005), is one where gender is seen as a form of social doing

JELTL (Journal of English Language Teaching and Linguistics), 4(2), 2019 


\section{Bouhout Najib}

(West \& Zimmerman, 1987). The importance of talk in the new paradigm is paramount and the analysis of the interactional performance of gender in mundane conversations has received primary attention (Kitzinger, 2000).

Within this paradigm, Membership Categorization Analysis (henceforth MCA) stands out as especially useful. The ethnomethodological roots MCA emanates from tally with the modern view of gender as a form of identity work (Edwards, 1998) and as a social accomplishment (Kessler \& McKenna 1978, 22). In conducting the business of daily life through talk-in-interaction, people categorize each other in order to achieve particular interactional outcomes. Talk-in-interaction is the site where the action import of categorization work is most visible.

This article explores the ways interactants enlisted gender categories in the service of realizing pragmatic actions in the course two mundane conversations. First, the article summarizes the key notions in MCA and reviews their contribution to the study of gender and discourse. Second, it offers an analysis of two conversational excerpts where the word manliness is used for the specific action of advice giving, in the first conversation, and blame attribution in the second. It is hoped that the article contributes to the recently emerging literature that takes an ethnomethodological turn both in the study of gender, discourse, and social action (Stokoe, 2012; 2010; 2006; 2000; Stokoe \& Edwards, 2012; Wilkinson \& Kitzinger, 2008; Kitzinger \& Rickford, 2007).

\section{LITERATURE REVIEW}

\subsection{Key ideas in MCA}

Hester and Eglin (1997) discuss the principles of MCA through tracing their beginnings in Sacks work. Sacks starting point was his observation that a person can be categorized in many ways, all of which are referentially adequate (Schegloff, 2007b). A person is not only a man or a woman but he/she is also a Muslim, a professor, a white, a leftist, etc., all at the same time. Sacks' problem was one of accounting for the use by parties to talk of one category rather than another. As such, he aimed to describe the formal structures that organize categorization of people in conversation (Díaz, 2012). Sacks developed the principles of MCA following an analysis of a girl's story 'the baby cried mommy picked it up' (Sacks, 1995, Vol. 1, p. 236).

Initially, Sacks observes that recipients of the story hear links between the categories 'baby' and 'mommy', specifically, that the latter is the mother of the former. This hearers do in the absence of explicit possessive adjectives (Hester \& Eglin 1997; Lepper, 2000; Schegloff, 2007b). The device 'family', of which the categories 'baby' and 'mommy' are members, provides the link between the two categories (Sack, 1995, Vol 1, p. 238). A device allows the grouping of categories together. It is "made up of a group of categories [which make it possible to] classify a population" (p. 40).

Categories become members of particular devices through two rules of application: the economy rule and the consistency rule (Sacks, 1995, Vol 1, p. 246). The consistency rule stipulates that if a person is categorized using a given device, then subsequent categorizations of other persons are selected from that same device. A rule of "one-deviceat-a-time" seems to underlie the consistency rule (Lepper, 2000, p. 18-19). 
On the other hand, the economy rule explains referential adequacy (Silverman, 1998; Schegloff, 2007b), which refers to the preference in interaction for the minimal use of categories. Since, as said above, there exist virtually infinite ways to categories people, interactants use categories minimally in such a way as to ensure that people referred to are adequately identifiable with relations to sets of activities, obligations and inferences attached to them, and which interactants see as relevant at the moment of interaction. Usually, as Psathas (1999) notes, "[o]ne membership category is adequate for describing a member of some population" (p. 143). The use of mommy in the story above makes hearable her role of mother (not wife, nor doctor, nor indeed any other role she might concurrently have) to pick up the crying baby. Therefore, the device family and the two rules of consistency and economy warrant that the two membership categories mentioned in the story are referentially adequate, such as to ensure that the intended links between mommy and baby are made sense of by hearers (Lepper, 2000; Silverman, 1998).

Another key concept of MCA is 'duplicative organization' (Sacks, 1995, Vol. 1, 247). It refers to interactants' presumption that categories fall into team-like groups, whereby invoking a given category "will automatically invoke inferences about who else might be expectably present" (Lepper, 2000, p. 21). As in teams, the roles, rights, obligations, and activities are organized hierarchically, symmetrically or asymmetrically. Dupicative organization is the common-sense logic to hear and see unitness in categories in talk (Psathas, 1999).

Duplicative organization is most clearly seen in Standardized Relational Pairs (SRPs) (husband/wife, teacher/student, doctor/patient), such that a pair, as Lepper (2000) notes, "constitutes a locus for rights and obligations" (p. 17). Again, with reference to the story above, not only 'baby' and 'mommy' belong to the same family, and mommy is the mommy of the baby, but also 'crying' is a category-bound activity of children and 'picking up crying babies' is categorially bound to mothers. In this sense, not only categories and their category-bound activities are co-selected (Psathas, 1999), but the selection of specific categories and activities invokes for both speakers and hearers notions of attributes, motives, rights and obligations (Watson, 1997; 1978; Jayyusi, 1984).

In short, then, MCA is the study of common sense methods that enable inferences to be made from the referential and descriptive use of categories and the study of how these are deployed to do actions in interaction (Fitzgerald, Housley, \& Butler, 2009; Lepper, 2000).

\subsection{MCA and gender as a form of social action}

MCA has recently made major headways as a viable discourse analytic method. It has proved fertile in the study of gender (Wilkinson \& Kitzinger, 2008). Especially useful is its insistence on moving away from concerns with abstract gender identities to a focus on societal members' practical orientation to and deployment of gender in conversation.

Since categorization is an action, MCA analysts study conversation for what societal members do with gender categories, how they sustain their commonsense knowledge of them, and what their interactional import to the understanding of talk in conversation. Stokoe (2004), for example, analyzed the interaction of a group of university students in a seminar. In naming a scribe for the group, one student suggested another, the only female present, for the task. In the excerpts Stokoe analyzed, the student juxtaposed the category secretary and 


\section{Bouhout Najib}

female, making hearable the link between the two within a single device (female professions). Thus, the student excluded males in the group from being incumbents of the category scribe by implying a duplicatively organized contrast between male professions and female professions, and by exploiting the standardized relation pair of female/male.

Stokoe argues that the student used the categories of 'scribe' and 'female' to "construct a version of the social order" that ties the female student to the category-bound activity of note-taking rather than to "active collaboration in the development of the group's ideas" (p. 116). Thus constructed, the link literally effected her exclusion.

In Weatheral's (2002) view, and with regards to gender, categorization involves a dimension of negotiation. Weatheral recorded children's interaction to solve problems of gender assignment for dolls of ambiguous gender she gave them. Her study demonstrates that becoming a competent social being involves the ability to move from negotiating gender status, through the ability to categorize, toward "more seamless construction of gender" (p. 769), largely the prerogative of adults.

For other authors, such as Antaki and Widdicombe (1998), membership categorizations are acts of identity ascription in interaction. One resource that interactants draw on to establish identity is what Nilan (1994) refers to as "boundary maintenance in everyday gendered discourse" (p. 152). Nilan analyzed dialogues in play scripts written by students for each other and, based on their analysis, argued that the assignment of gender membership reveals the "the operative centrality of the binary opposition gay-straight within the dominant discourse of masculinity" (p. 146).

\section{DATA}

In keeping with the MCA policy of using naturally occurring talk in analyzing categorization work, data for this paper consist of mundane conversational excerpts taken from a pool of conversations (30 in total) recorded as part of an ongoing $\mathrm{PhD}$ project. The first excerpt occurred during after-dinner talk among friends where the author was present but did not participate. The second episode is taken from another after-dinner episode that a participant recorded for the author. Participants' names are anonymized. As is the practice in MCA, Jefferson's (2004) transcription system is used to transcribe the audio recordings (see appendix). The Moroccan Arabic data is transcribed using broad phonetic transcription. A gross English translation each line in the transcripts (see appendix). Gross translation enables readers unfamiliar with Moroccan Arabic to grasp the general meaning of the talk and to focus on categories without the distractions of narrow translations (Have (2007) on data translation). The analysis is carried on the original recordings and transcripts and not on their translation.

\subsection{The relevance of gender in everyday life: A first example}

The excerpt comes from interaction around dinner table at Abdessamad's house. Prior to this sequence, Samir was telling the others about his relationship with a girl he met a few months ago. The girl used to support him financially when he was broke. Earlier in the story, He mentioned that the girl ended their relationship because of his refusal to move forward with the relationship and see her father. The break up happened soon after Samir's financial 
situation had gotten better (after his reception of back pay). This last bit of new triggered the conversation below.
1. Aziz:
waxxa xssək dirlha $\int \mathrm{i}$ kado=
2.
Though you should make her a gift
=wrozu:la
And it's manliness
3.
=wkajna wlla lla axaj Səbdssama:d ?=
And isn't it brother Səbdssama:d ?
4. Abdessamad: =kajna.
It is.
5. Samir: $\quad$ wa:: maktab $\int^{\circ}$ maktab $\int^{\circ}$.
Well it wasn't meant to be.

Sequentially, Aziz's turn is made of three TCUs (Turn constructional units, lines 1, 2, and 3) (Sacks et al., 1974). The first is addressed to Samir, in which he is strongly urged to offer his girlfriend a gift (line 1). Apparently, the second is addressed to both Abdessamad and Samir, where the reason for the suggestion (of giving a gift) is specified as manliness (line 2). The third TCU seeks Abdessamad's agreement on both the suggestion and its rationale (line 3 ).

The three TCUs in the turn are latched to each other (the = sign in the transcript). Interactionally, what it is latched are the suggestion, the ground on which it is made, and an agreement-seeking yes-no question. Knowing that latching is one technique to withhold speakership (Sacks et al., 1974), Aziz uses it both sequentially to prevent turn transfer and interactionally to prevent potential opposition to the suggestion. Note that, were Aziz to present the suggestion with no rationale, the next speaker after line 1 could question the reason a gift should be given. The second TCU is therefore latched to the first so as to preempt any next contribution that questions the rationale of his suggestion.

Moreover, it is interesting to note that the reason consists of the abstract noun rozu:la (manliness). Evidently, the noun constructs a link - that the action of gift-giving is predicated on manliness and the link applies to Samir somehow. Somehow, because Aziz does not explicitly invoke the category 'man' for Samir, but relies on the viewer's maxim (i.e. as they appear so things are (Silverman, 1998). It leaves to the recipients to see how manliness acts is predicated on Samir as a man. In other words, the interlocutors can hear and see Aziz's orientation to the Standardized Relational Pair 'malef/emale' and its attending rights and obligations.

By using the abstract noun, Aziz morally and implicitly binds Samir to his own gender by urging him to do a manly act while, as I argue below, at the same time avoiding any negative implication to his gender identity. This management of moral implications through the careful selection of rozu:la is detailed in the paragraphs below.

First, it is noteworthy the absence of anything in rozu:la that makes the act of giftgiving follow from it either logically or semantically. It is not even a culturally expected manly practice (gifts are in fact given by men and women to each other for a variety of reasons other than being a property of being a man or a woman). Making the act part of the collection manly practices and simultaneously bind it to Samir, constitutes here an instance 


\section{Bouhout Najib}

of what Jayussi (1984) calls "category-generated activity" (p. 37). Category-generated activities are constructed for the occasion, locally, and are based on the relevant categorization of a person invoked at the moment of interaction. Similarly here, Aziz's suggestion of gift-giving is only tied to manly practices for the purposes of the situation and, as said above, does not follow either logically or semantically from the facts of gender (whatever that is). The viewer's maxim makes it possible for him to relevantly invoke the gender of Samir, and it is as a gendered practice that the suggestion is morally significant.

Second, manliness is culturally acknowledged but is nowhere pre-defined in advance. It is always an interactive issue for the participants. Interactants need only register that one participant invokes a general moral principle, here to the effect that men act manly. They need not check whether gift-giving figures in a cultural list subsuming all the practices bound to men, for, indeed, what constitutes part of this list cannot be specified in advance of interaction. Since Aziz constructs the action of gift-giving as a manly practice in situ in that conversation, it is in this sense a category-generated activity.

Third, the parties to the episode can negotiate whether or not complying with the suggestion on the part of Samir is manly, but not whether he is (not) a man if he complies, or does not comply, with the suggestion. This is no superficial difference. In order to see what stakes are involved and managed, consider the implications if Samir refuses, or chooses not, to perform the act.

1. He did not give a gift to his former girlfriend; so, that isn't manly.

2. He did not give a gift to his former girlfriend; so, he's not a man.

Clearly, statement 1 is the kind of moral reasoning at work in the excerpt above. As said above, the open-texture of the device 'manliness' allows for disagreement without it directly engaging gender. On the other hand, statement 2 invokes gender on-record in order to pass a judgment that undeniably tints Samir's moral character qua a man. This being the case, the reasoning in 2 could lead to disaffiliation. It could even amount to an antagonistic action if meant seriously, as indeed the expression not a man is routinely used as an insult in the Moroccan context- insulting a man by denying him his gender identity.

It is in that light that Aziz's talk can be seen as strategically assembled out of gender and moral categorization. The use of rozu:la is sensitive to the commonsense fact that evaluation of persons is stronger, morally speaking, than the evaluation of practices (properties of manliness). Morally speaking, for a man not be a man is more pejoratively implicative than for a practice to be unmanly (therefore immoral in this case). The use of an abstract noun demonstrates that interactants are aware of, and can insinuate, implications that could be drawn when gender categories are interactionally used in conversation.

There is, in fact, more to the organization of the talk above that shows how it is finely tuned to the gender basis of the moral principle invoked. To appreciate its design, notice the turn's similarity to the widely known organization of inserted adjacency pairs. Consider the example below from Laddicoat (2007, p. 145). (FPP is First Pair Part and SPP Second Pair Part).

Harry:

Aren't you supposed to go up there with John though?

(FPPbase) 


\begin{tabular}{|c|c|c|c|c|}
\hline Joy: & \multicolumn{2}{|l|}{ Wha'? } & \multicolumn{2}{|l|}{ (FPPinsert) } \\
\hline Harry: & \multicolumn{2}{|c|}{ Y' aren't goin' up there with John. } & (SPPinsert) & \\
\hline Joy: & \multicolumn{2}{|c|}{ na:h that fell through weeks ago. } & (SPPbase) & \\
\hline \multicolumn{5}{|c|}{ The similarity to Aziz's constituent TCUs is shown as follows, } \\
\hline 1. & \multirow[t]{4}{*}{ Aziz: } & \\
\hline 2 & & \multicolumn{3}{|c|}{ Though you should make her a gift } \\
\hline & & \multicolumn{2}{|l|}{ And manly } & 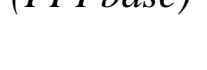 \\
\hline 3. & & \multicolumn{2}{|c|}{$\begin{array}{l}=\text { wkajna wlla lla axaj ৎəbdssama:d ?= } \\
\text { And isnt't a manly act brother ؟əbdssama:d ? }\end{array}$} & $\begin{array}{l}\text { (FPPinsert }) \\
?\end{array}$ \\
\hline 4. & Abdessamad: & \multicolumn{2}{|l|}{$\begin{array}{l}\text { =kajna. } \\
\text { It is. }\end{array}$} & (SPPinsert) \\
\hline 5 . & Samir: & \multicolumn{2}{|l|}{ wa:: maktab $\int^{\circ}$ maktab ${ }^{\circ}$. } & (SPPbase) \\
\hline
\end{tabular}

Adjacency pairs point to a general principle in mundane conversation. That is the principle of contiguity (Schegloff, 2007a, p. 14). Schegloff explains that in talk-ininteraction, there is a preference for FPP and SPP in an adjacency pair to be placed as adjacent to each other as possible. In adjacency pairs where insertion occurs, the preference for contiguity is maximally preserved for the insertion sequence (notice that an organisation such as FPPbase, FPPinsert, SPPbase, SPPinsert would make parts of neither pair contiguous).

Notwithstanding the broad similarity of Aziz's turn to insertion sequences, its peculiarity lies in his selection of a different next-speaker in each FPP. FPPbase selects Samir as next speaker whereas FPPinsert selects Abdessamad as next speaker. Given the contiguity principle, Abdessamad has the right to speak after the FPPinsert, to produce SPPinsert. Naturally, the explicit selection of Abdessamad by his first name (line 3) blocks the way for Samir to respond only to the first part of Aziz's turn - that is, to respond only the suggestion made in line 1. Had the slot been open after FPPbase, objection to the suggestion could have occurred, for the latter would be vulnerable to opposition at that place in conversation where a rationale for it is absent.

Formally, the FPPinsert is a polar question designed to prefer type-conforming answer - either a yes or no) (Raymond, 2003). On the action level, the turn is an agreement-seeking action that, as Pomrantz and Heritage (2012) explain, makes agreement the preferred next action. At both levels then, Aziz's turn maximizes the chances for a yes-answer that agrees with his proposition. And Abdessamad indeed answers with a kajna (yes), an answer that is both type-conforming and in line with the preference for agreement (no delay or hesitation markers).

Using the insertion sequence and the order of speakership it enforces, Aziz is able to secure the agreement of Abdessamad first before Samir can respond. Securing the agreement of the former makes any potential challenge on Samir's part a difficult task, for it would mean he is challenging not one but two interlocutors, and on a matter on which they both concur: that a man, qua a man, should act manly. It is in this way that the design of Aziz's turn exploits the conversational structure of insertion sequences to effect a peculiar order of 


\section{Bouhout Najib}

next-speakers, which immunizes the suggestion, and its grounds, against opposition. The excerpt, in short, shows the way one interactant enlists gender in the service of the action of suggesting based on gendered reasoning.

\subsection{The relevance of gender in everyday life: A second example}

The second example is recorded on a different occasion and illustrates another way in which the device of gender is used. Here, it is used by the speaker to blame one of his interlocutors. I take the interactional episode bit by bit in order to detail how the action and categorization unfold.

1. Hakim: kifə katzi kt 1 te:k lflu:s?

How come she comes and gives you money?

2. Ihsan: kaddəwwər $\mathrm{m} \uparrow \varsigma$ :aja.

She offers its to me.

The excerpt comes after the end of a story told by Ihsan. Technically, Hakim's turn (line 1) is a repair sequence. The repair does not relate to a hearing problem. kifaf (how come) requests clarification on an action previously reported - of money giving- and therefore, constructs the action as accountable (Sacks, 1995, Vol. 1, lecture 10). Though he understands the statement, Hakim orients to the action of money-giving as problematic and, as such, requires further talk to be, for him, properly grasped.

The implication of Hakim's repair is that money-giving somehow violates an expectation. The nature of the expectation only becomes clear in subsequent talk.

3. Hakim: hadi rozu:la daba kaddəwwər mSa:k hijja bənt?

4. Ihsan: $\quad{ }^{\circ} \mathrm{u} \int \mathrm{nu}^{\circ}$ ?

So what?

Hakim openly orients to a moral principle and, in holding Ihasn accountable for violating that principle through his action of money-taking, orients to the action as blameworthy. The blaming act clearly constitutes an obvious threat to Ihsan's face.

Again, it is interesting that, following an FPP of a polar question (line 3), Ihsan does not provide an answer but rather reroutes the question back to Hakim, dodging both the question and the moral choices it forces him to make.

5. Hakim: rozu:la hadi axaj kam[al?

Is it manliness brother Kamal?

6. Kamal:

[wəllah ma rozu:la.

7. Hakim: [(h)hehehehe

By God it's not manliness. 
Hakim brings the moral accountability of Ihsan's action up in a new turn (line 5). The continuity of the relevance of the latter's accountability seems to emanate from the challenging character of his response (line 4) to the polar question. Since it counters (Laddicoat 2007, p. 109; Schegloff 2007a, p. 17) Hakim's question rather than answers it, an answer is still pending.

The categories Hakim uses to construct his blame figure centrally in the pursuit of the answer - rozu:la, bant (girl) and, by extension through the SRP man/woman, Ihsan's gender. By bringing the moral question to the surface of talk after the termination of Ihsan's story, and by directing his answer first to the story-teller himself and second to a fellow listener, Hakim takes it, and displays to his interlocutors that he takes it, that a satisfactory account is still missing.

That the question is directed to a third party (Kamal) is itself interesting. It may be read as an attempt on the part of Hakim to secure the former's alignment with the moral principle introduced by him and violated by Ihsan. If this is the case, then the alignment-seeking strategy is interactionally similar to the one discussed above in the case of Samir, even if the outcome is not the same. Below is the above excerpt repeated with further talk.

5. Hakim: rozu:la hadi axaj kam[al?

Is it manliness brother Kamal?

6. Kamal:

[wəllah ma rozu:la.

7. Hakim: [(h)hehehehe

By God it's not manliness.

8. Ihsan: [wllah ila rozu:la=wəlla[hima nS-

By God it's manliness= by God I don't c-

The shape of Kamal's answer (line 6) is peculiar in that it is "type unconforming" (Raymond, 2003), i.e., it signals, by virtue of the additional emphasis of wellah and the repetition of part of the question, an even stronger agreement than a yes would register. It also displays a stronger claim of epistemic authority (Heritage \& Raymond 2012, 185). Rather than just affirming the claim made in Hakim's question, Kamal is actively confirming - or co-constructing - its moral basis and its implication for their current purposes. Repetitional answers, as Heritage and Raymond show, make claims to "more epistemic rights over the information required than the original polar question conceded" (p. 185). Not surprisingly then, it is that same specific turn design Ihsan exploits (line 8) to resist the agreement of the other two participants over the immorality of his own action.

Again, what is remarkable in the whole episode is the fact that Hakim constructs his blame against Ihsan only indirectly through a category-generated activity used to illustrate a mundane moral principle. Hakim takes Ihsan's action as a violation to the general principle that men do no take money from women.

Also, and similar to the first example above, Hakim mitigates the threat to Ihsan's face, consequent to his asking for an account, and at the same time manages the implications of binding the activity of money-taking to men. Hakim is not saying to Ihsan that he is not a man to take money from a girl, for that would constitute a severe threat to latter's gender identity, but he locally constructs the activity as part of an open-textured collection of manly practices.

JELTL (Journal of English Language Teaching and Linguistics), 4(2), 2019 


\section{Bouhout Najib}

Given that Hakim holds the practice, not the person, accountable, the openness of the collection makes it possible to challenge the constructed boundedness of the practice to gender. And Ihsan does indeed opt to challenge it.

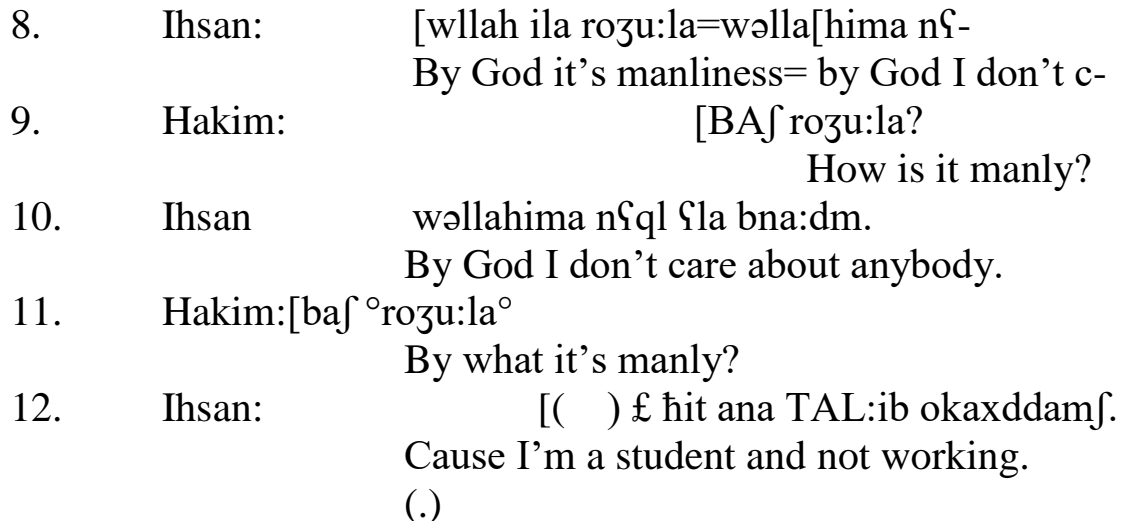

Ihsan's turn (line 8) parallels that of Kamal in that it displays an equally strong disagreement om similar epistemic authority. In line 12 he unties the link between his action and his gender by self-categorizing as a student, thus succeeding in both providing an account for his action and discrediting the interactional relevance of his gender identity hitherto exploited by the other parties.

Ihsan highlights the relevance of self-categorizing as a student by explicitly bringing up a specific feature of it- joblessness. The invocation of this feature allows him not only to dispute the moral principle but also to invoke new grounds on which his act can be read. The new reading now does away with the relevance of his gender altogether by de-gendering (Kitzinger \& Rickford 2007, p. 219) the activity of money taking.

Overall then, the analysis of the second episode highlights another way another interactant deployed gender in interaction. Namely, the interactants used gender categorization to blame another for engaging in an unmanly practice. The blame works essentially because the party blamed is categorized as a man and, therefore, bound to act manly. The blame is administered not on the basis of demographic or biographic details, age, job, socio-economic status, etc., but on the basis of a gender categorization, deployed in the service of constructing a practice as gendered and morally deplorable. Also, it is interesting that, for the party blamed to defend himself, he tried to degender the deed he is blamed for.

\section{DISCUSSION}

The implications of MCA for gender studies are many, ranging from theoretical to methodological to the status of categories as one important locus of analysis in discourse studies. One methodological problem is especially relevant for the points raised by the article. It relates to how social issues, including moral ones, are made sense of as gendered.

Schegloff (2005) observes that is a substantial number of cases, social problems involve categorizing people in different ways and taking a stance towards those categorized. Schegloff's argument is that, since categorization work informs understanding of social behavior, its interactional aspects can be studied both for what they tell about members' 
orientations towards people and their courses of conduct (450). In other words, talk can be studied to reveal what social problems are, by whom they are made problems, to whom they are problems, and what their problematicity entails for the parties concerned and for society at large. The point is not that the analyst invokes categories (like gender) a priori to explain social phenomena, for that would be an ad hoc act (Schegloff, 1997). Rather, the analyst is required to show from the course of interaction that and how the categories she/he claim as relevant are the ones which inform the conduct of members in that interaction. Hence, the analysis of social issues should, by analytical rigor, be understood in terms of societal members themselves, for social issues are members' issues in the first place. It does not do to claim that a category, be it gender, class, profession, etc., is relevant because the analyst says so. I would claim following Schegloff (1997), that the unwarranted imposition of gender on data constitutes an act of "theoretical imperialism" (p. 167). It is no less than arbitrarily imposing on data an analytic gloss (men's talk or women's talk) potentially relevant, but whose relevance remains to be empirically demonstrated.

More broadly, the problem of categorization is but a part of a larger problem for discourse analysts in general. Proponents of all approaches to discourse agree that language is primarily a socially contexted phenomenon; however, they practically all disagree as to what the proper limits on context should be that allow for an adequate description of discourse. Gee calls this tension between discourse and context the framework problem. It refers to the fact that context ranges from very narrow contextual contingencies to larger social or historical factors. Whatever layer of context one works with, there is always the possibility of considering extra (or intra) layers that can substantially change how an utterance is understood (Gee 2004, p. 30).

In a sense, any choice of one contextual aspect rather than another seems arbitrary. This is in fact one reading of Gee's solution to the problem apparent, for example, in his call on discourse analysts to "offer arguments that the aspects of context they have considered, in a particular piece of research, are the important and relevant ones" (p. 32).

Phrased in this way, it is clear that Gee conceives of the framework problem as a methodological nuisance for the analyst, to be solved simply by choosing some contextual features, out of a myriad of others, and argue for their relevance. That contextual features are there up for grab and not empirically established is a point that Schegloff $(1991 ; 1997)$ vehemently criticizes. For Schegloff and conversation analysts in general, interactants are sentient being who themselves orient to their context under some formulation or formulations, who grasp their own conduct and that of others under the jurisdiction of some relevancies and not others; who orient to some of the identities they separately and collectively embody and, at any given moment, not others. (Schegloff 1997, 166).

As the analysis shows, MCA can indeed provide one way out of a multi-layered framework. Using MCA, the analyst is bound by the categorization work of interactants and has no right to stamp data with her own categories for the sake of theoretical or analytical concerns. Gender is relevant for the analyst as long as it is demonstrably relevant for societal members in their everyday conduct. This latter idea is a recent one, fully embraced by 


\section{Bouhout Najib}

contemporary scholars working in gender and discourse as, for instance, in Kitzinger's (2000) Feminist Conversation Analysis.

Scholars using MCA tend to agree as to the extent members' categories warrant the inclusion of gender as an analytic interest. Briefly, gender is analytically relevant where, implicitly or explicitly, it furbishes a cultural backdrop to social issues (Kitzinger, 2005) and is procedurally consequential for the course of interaction, i.e. contributes to the unfolding of action(s) in interaction (Speer, 2005).

\section{CONCLUSION}

This article investigated one dimension of the relevance and consequentiality of gender; namely, how it is used to provide the moral ground for two actions, suggestion and blame, in two different conversations. The analysis focused on the import of gender in providing the basis for moral principles invoked in the course of mundane talk. The categories and the moral principles they warrant served to reveal a world of what Stokoe and Edwards (2012) refer to in the title of their paper as "mundane morality". In short, the analysis detailed the descriptive and categorial procedures behind, and that allowed for, the accomplishment of gender categorization as a morally-binding issue for the parties to talk.

\section{REFERENCES}

Antaki, C., \& Widdicombe, S. (1998). Identities in talk. London: Sage Publications.

Burr, V. (1995). An introduction to social constructionism. London: Routledge.

Díaz, F. (2012). Category sets and category-bound activities: Identity from the standpoint of members. In N. Bozatzis \& T. Dragonas (Eds.), The discursive turn in social psychology(pp. 63-73). Retrieved from https://www.taosinstitute.net/the-discursive-turnin-social-psychology

Edwards, D. (1998). The relevant thing about her: Social identity categories in use. In C. Antaki \& S. Widdicombe (Eds.), Identities in talk (pp. 15-33). London: Sage Publications.

Fitzgerald, R., Housley, W., \& Butler, C. W. (2009). Omnirelevance and interactional context. Australian Journal of Communication, 36(3), 45-64.

Gee, P. J. (2004). Discourse analysis: What makes it critical? In R. Rogers (Ed.), An introduction to critical discourse analysis in education (pp. 19-50). New Jersey: Routledge.

Have, P. T. (2007). Doing conversation analysis. London: Sage Publications.

Heritage, J., \& Raymond, G. (2012). Navigating epistemic landscapes: Acquiescence, agency and resistance in responses to polar questions. In J. Ruiter (Ed.), Questions: Formal, functional and interactional perspectives (pp. 179-192). Cambridge: Cambridge University Press.

Hester, S., \& Eglin, P. (1997). Culture in action: studies in membership categorization analysis. Washington, D.C.: University Press of America \& International Institute for Ethnomethodology and Conversation Analysis.

Jayyusi, L. (1984). Categorization and the moral order. Boston: Routledge \& K. Paul. 
Jefferson, G. (2004). Glossary of transcript symbols with an introduction. In G. H. Lerner(Ed.), Conversation analysis: Studies from the first generation (pp. 13-23). Philadelphia: John Benjamins.

Kessler, S., \& McKenna, W. (1978). Gender: An ethnomethodological approach. Chicago: University of Chicago Press.

Kitzinger, C. (2000). Doing feminist conversation analysis. Feminism \& Psychology, 10(2), 163-193. doi:10.1177/0959353500010002001

Kitzinger, C. (2005). "Speaking as a heterosexual": (How) does sexuality matter for talk-inInteraction? Research on Language \& Social Interaction, 38(3), 221-265. doi:10.1207/s15327973rlsi3803_2

Kitzinger, C., \& Rickford, R. (2007). Becoming a 'bloke': The construction of gender in interaction. Feminism \& Psychology, 17(2), 214-223. doi:10.1177/0959353507076554

Lepper, G. (2000). Categories in text and talk A practical introduction to categorization analysis. London: Sage Publications.

Liddicoat, A. (2007). An Introduction to conversation analysis. London: Continuum.

Nilan, P. (1994). Gender as positioned identity maintenance in everyday discourse. Social Semiotics, 4(1-2), 139-162. doi:10.1080/10350339409384431

Pomerantz, A., \& Heritage, J. (2012). Preference. In T. Stivers \& J. Sidnell (Eds.), The handbook of conversation analysis (pp. 210-228).

Psathas, G. (1999). Studying the organization in action: Membership categorization and interaction analysis. Human Studies, 22(2-4), 139-162. doi:10.1023/a:1005422932589

Raymond, G. (2003). Grammar and social organization: Yes/no interrogatives and the structure of responding. American Sociological Review, 68(6), 939-967. doi: $10.2307 / 1519752$

Sacks, H. (1995). Lectures on conversation: Volumes I \& II. Oxford: Blackwell.

Sacks, H., Schegloff, E. A., \& Jefferson, G. (1974). A Simplest systematics for the organization of turn-taking for conversation. Language, 50(4), 696-735. doi: $10.2307 / 412243$

Schegloff, E. A. (1991). Reflections on talk and social structure. In D. Boden \& D. H. Zimmerman (Eds.), Talk and social Structure: Studies in ethnomethodology and conversation analysis (p. 44-70). Cambridge: Polity Press.

Schegloff, E. A. (1997). Whose text? Whose context? Discourse \& Society, 8(2), 165-187. doi:10.1177/0957926597008002002

Schegloff, E. A. (2005). On complainability. Social Problems, 52(4), 449-476. doi:10.1525/sp.2005.52.4.449

Schegloff, E. A. (2007a). Sequence organization in interaction: A primer in conversation analysis. Cambridge: Cambridge University Press.

Schegloff, E. A. (2007b). A tutorial on membership categorization. Journal of Pragmatics, 39(3), 462-482. doi:10.1016/j.pragma.2006.07.007

Silverman, D. (1998). Harvey Sacks: Social science and conversation analysis. Cambridge: Polity Press.

Smith, P. (1985). Language, the sexes and society. Oxford: Brasil Blackwell.

Speer, S. A. (2005). Gender talk: Feminism, discourse and conversation analysis. London: Routledge. 


\section{Bouhout Najib}

Stokoe, E. (2006). On ethnomethodology, feminism, and the analysis of categorial reference to gender in talk-in-interaction. The Sociological Review, 54(3), 467-494. doi:10.1111/j.1467-954x.2006.00626.x

Stokoe, E. (2010). Gender, conversation analysis, and the anatomy of membership categorization practices. Social and Personality Psychology Compass, 4(7), 428-438. doi:10.1111/j.1751-9004.2010.00261.x

Stokoe, E. (2012). Moving forward with membership categorization analysis: Methods for systematic analysis. Discourse Studies, 14(3), 277-303. doi:10.1177/1461445612441534

Stokoe, E., \& Edwards, D. (2012). Mundane morality: Gender, categories and complaints in familial neighbour disputes. Journal of Applied Linguistics and Professional Practice, 9(2), 165-192. doi:10.1558/japl.v9i2.25735

Stokoe, E. H. (2000). Toward a conversation analytic approach to gender and discourse. Feminism \& Psychology, 10(4), 552-563. doi:10.1177/0959353500010004018

Stokoe, E. H. (2004). Gender and discourse, gender and categorization: Current developments in language and gender research. Qualitative Research in Psychology, l(2), 107-129. doi:10.1191/1478088704qp007oa

Watson, D. R. (1978). Categorization, authorization and blame - negotiation in conversation. Sociology, 12(1), 105-113. doi:10.1177/003803857801200106

Watson, R. (1997). Some general reflections on 'categorization' and 'sequence' in the analysis of conversation. In S. Hester \& P. Eglin (Eds.), Culture in action: Studies in membership categorization analysis (pp. 47-76). Washington, D.C.: University Press of America.

Weatheral, A. (2002). Towards understanding gender and talk-in-interaction. Discourse \& Society, 13(6), 767-781. doi:10.1177/0957926502013006756

West, C., \& Zimmerman, D. H. (1987). Doing gender. Gender \& Society, 1(2), 125-151. doi: $10.1177 / 0891243287001002002$

Wilkinson, S., \& Kitzinger, C. (2008). Using conversation analysis in feminist and critical research. Social and Personality Psychology Compass, 2(2), 555-573. doi:10.1111/j.1751-9004.2007.00049.x

\section{Appendix: Transcription symbols}

[ beginning of overlap.

$=\quad$ chained talk.

(.) short gap of less than a second.

: $\quad$ prolongation of the sound.

( ) talk unheard or unclear on tape.

- $\quad$ cut off.

$\circ$ talk quieter than usual.

ABC loud sounds.

Underline stress.

(1.0) silence time is seconds. 